Journal of Organometallic Chemistry, 276 (1984) 185-192

Elsevier Sequoia S.A., Lausanne - Printed in The Netherlands

\title{
NEW NEUTRAL AND CATIONIC DICYCLOPENTADIENYLNIOBIUM COMPLEXES
}

\author{
F.A. URBANOS, M. MENA, P. ROYO and A. ANTIÑOLO \\ Departamento de Quimica Inorgánica, Facultad de Ciencias, Universidad de Alcalá de Henares (Spain) \\ (Received May 7th, 1984)
}

\section{Summary}

$\left(\eta^{5}-\mathrm{C}_{5} \mathrm{H}_{5}\right)_{2} \mathrm{NbX}\left(\mathrm{PMe}_{3}\right)(\mathrm{X}=\mathrm{Cl}, \mathrm{Br})$ was prepared by reducing $\left(\eta^{5}-\mathrm{C}_{5} \mathrm{H}_{5}\right)_{2} \mathrm{NbX}_{2}$ with $\mathrm{Na} / \mathrm{Hg}$ amalgam in the presence of $\mathrm{PMe}_{3} .\left(\eta^{5}-\mathrm{C}_{5} \mathrm{H}_{4} \mathrm{Me}\right)_{2} \mathrm{TaCl}\left(\mathrm{PMe}_{3}\right)$ was obtained analogously. The reaction of $\left(\eta^{5}-\mathrm{C}_{5} \mathrm{H}_{5}\right)_{2} \mathrm{NbCl}\left(\mathrm{PMe}_{3}\right)$ with $\mathrm{AgBF}_{4}$ gave metallic silver and cationic $\left[\left(\eta^{5}-\mathrm{C}_{5} \mathrm{H}_{5}\right)_{2} \mathrm{NbCl}\left(\mathrm{PMe}_{3}\right)\right]^{+}$, which reacts with $\mathrm{OPPh}_{3}$ to give $\left[\left(\eta^{5}-\mathrm{C}_{5} \mathrm{H}_{5}\right)_{2} \mathrm{Nb}\left(\mathrm{OPPh}_{3}\right)\left(\mathrm{PMe}_{3}\right)\right]^{2+}$ Cationic halide complexes [( $\eta^{5}-$ $\left.\left.\mathrm{C}_{5} \mathrm{H}_{5}\right)_{2} \mathrm{NbClL}\right]^{+}$are also formed from $\left(\eta^{5}-\mathrm{C}_{5} \mathrm{H}_{5}\right)_{2} \mathrm{NbCl}_{2}$ by abstraction of chloride with $\mathrm{AgBF}_{4}$ in the presence of the ligand, $\mathrm{L}=\mathrm{CH}_{3} \mathrm{CN}$ or $\mathrm{OPPh}_{3}$. When $\mathrm{L}$ is acrylonitrile, the dinuclear species $\left\{\left[\left(\eta^{5}-\mathrm{C}_{5} \mathrm{H}_{5}\right)_{2} \mathrm{NbCl}\right]_{2}\left(\mu-\mathrm{CH}_{2}=\mathrm{CHCN}\right)\right\}^{2+}$ is obtained. Attempts to isolate alkylniobium(III) complexes by alkylation of the corresponding halide complexes or by reduction of the haloalkylniobium(IV) derivatives were unsuccessful; no $\left(\eta^{5}-\mathrm{C}_{5} \mathrm{H}_{5}\right)_{2} \mathrm{NbCl}\left(\mathrm{CH}_{2} \mathrm{C}_{6} \mathrm{H}_{5}\right)$ was obtained and treatment of $\left(\eta^{5}-\mathrm{C}_{5} \mathrm{H}_{5}\right)_{2} \mathrm{Nb}\left(\mathrm{CH}_{2} \mathrm{C}_{6} \mathrm{H}_{5}\right)_{2}$ with halogen gave $\left(\eta^{5}-\mathrm{C}_{5} \mathrm{H}_{5}\right)_{2} \mathrm{NbI}_{2},\left(\eta^{5}-\mathrm{C}_{5} \mathrm{H}_{5}\right)_{2} \mathrm{NbBr}_{3}$ and $\left(\eta^{5}-\mathrm{C}_{5} \mathrm{H}_{5}\right)_{2} \mathrm{NbX}_{2}^{+} \mathrm{X}_{3}^{-}(\mathrm{X}=\mathrm{Br}, \mathrm{I})$.

\section{Introduction}

The small number of cationic dicyclopentadienylniobium(IV) complexes described were all obtained from haloniobium(IV) derivatives [1]. We describe here an alternative method using niobium(III) compounds as starting reagents. Several of these niobium(III) complexes have been prepared previously [2, and refs. therein] but little is known about their chemical behaviour, especially their resistance towards alkylation [3]. The best method of obtaining these alkylniobium(III) complexes involves the reduction of haloalkylniobium(IV) compounds, which cannot always be isolated, as we describe below for the benzyl derivative.

\section{Trimethylphosphineniobium(III)}

We chose $\mathrm{PMe}_{3}$ as a high $\pi$-acidic ligand with low steric requirements which forms stable metal-ligand bonds. The ligand was obtained from the complex $\mathrm{AgI} \cdot \mathrm{PMe}_{3}$ obtained by a modification of the usual method [4]. 
The reduction of THF solutions of $\left(\eta^{5}-\mathrm{C}_{5} \mathrm{H}_{5}\right)_{2} \mathrm{NbX}_{2}$ with one equivalent of $\mathrm{Na} / \mathrm{Hg}$ amalgam in the presence of $\mathrm{PMe}_{3}$ gives green crystals, which were characterised as complexes I and II on the basis of their analytical compositions shown in Table 1.

$$
\begin{aligned}
\left(\eta^{5}-\mathrm{C}_{5} \mathrm{H}_{5}\right)_{2} \mathrm{NbX}_{2}+\mathrm{Na} / \mathrm{Hg}+\mathrm{PMe}_{3} \rightarrow & \left(\eta^{5}-\mathrm{C}_{5} \mathrm{H}_{5}\right)_{2} \mathrm{NbX}\left(\mathrm{PMe}_{3}\right)+\mathrm{NaX} \\
& (\mathrm{I}, \mathrm{X}=\mathrm{Cl} ; \\
& \text { II, } \mathrm{X}=\mathrm{Br})
\end{aligned}
$$

The red complex $\left(\eta^{5}-\mathrm{C}_{5} \mathrm{H}_{4} \mathrm{Me}\right)_{2} \mathrm{TaCl}\left(\mathrm{PMe}_{3}\right)$ (III) was obtained analogously from the dichlorotantalum(IV) complex.

The products are unstable in air as solids, but may be kept unchanged under dry $\mathrm{N}_{2}$. They are soluble in THF, benzene, and toluene, and insoluble in diethyl ether and alkanes.

The remarkable stability of $\mathrm{I}$ contrasts with that of its $\mathrm{PEt}_{3}$ analogue [2], which could not be isolated as a solid. However $\mathrm{PMe}_{3}$ is readily displaced when $\mathrm{CO}$ is bubbled through a THF solution of I to give the corresponding carbonyl complex [5]. No reaction takes place with ethylene.

The IR spectra of complexes I-III show characteristic $\left(\eta^{5}-\mathrm{C}_{5} \mathrm{H}_{5}\right)$ absorptions at $3050-3100,1100,1000$ and $850 \mathrm{~cm}^{-1}$ and $\mathrm{PMe}_{3}$ absorptions at 1290 and $950 \mathrm{~cm}^{-1}$. Complexes I and III show an absorption at $250 \mathrm{~cm}^{-1}$ assignable to the $\nu(\mathrm{M}-\mathrm{Cl})$ stretching vibration, which is not observed in the region above $200 \mathrm{~cm}^{-1}$ for the corresponding $\nu(\mathrm{M}-\mathrm{Br})$ in complex II.

The ${ }^{1} \mathrm{H}$ NMR spectra for complexes I and II indicate the presence of two equivalent $\left(\eta^{5}-\mathrm{C}_{5} \mathrm{H}_{5}\right)$ rings (singlet at $\delta 4.63$ and $\delta 4.58 \mathrm{ppm}$, respectively). The substituted rings are also equivalent in complex III and give three ${ }^{1} \mathrm{H}$ resonances $(\delta$ $4.70, \delta 4.29$ and $\delta 3.80 \mathrm{ppm})$ and one singlet $(\delta 1.87 \mathrm{ppm})$ due to the ring methyl groups. The ${ }^{1} \mathrm{H}$-methyl resonances of $\mathrm{PMe}_{3}$ appear as a doublet at $\delta 0.83 \mathrm{ppm}$ $J(\mathrm{H}-\mathrm{P}) 8 \mathrm{~Hz}$ for $\mathrm{I}, \delta 0.83 \mathrm{ppm} J(\mathrm{H}-\mathrm{P}) 6.4 \mathrm{~Hz}$ for II and $\delta 0.94 \mathrm{ppm} J(\mathrm{H}-\mathrm{P}) 3.7 \mathrm{~Hz}$ for III. These data suggest that the structures are the same as those propossed for similar complexes [2].

\section{Cationic complexes}

Complex I reacts with $\mathrm{AgBF}_{4}$ with deposition of metallic silver to give the cationic complex IV.

$\left(\eta^{5}-\mathrm{C}_{5} \mathrm{H}_{5}\right)_{2} \mathrm{NbCl}\left(\mathrm{PMe}_{3}\right) \underset{-\mathrm{Ag}}{\stackrel{\mathrm{AgBF}_{4}}{\longrightarrow}}\left[\left(\eta^{5}-\mathrm{C}_{5} \mathrm{H}_{5}\right)_{2} \mathrm{NbCl}\left(\mathrm{PMe}_{3}\right)\right]^{+} \mathrm{BF}_{4}^{-}$

Analogous halide complexes cannot be obtained from IV by replacement of the ligand because $\mathrm{Cl}$ dissociates rather than $\mathrm{PMe}_{3}$ in the presence of donor solvents such as THF and acetone. The solvated dication could not be isolated, but the addition of $\mathrm{OPPh}_{3}$ gives the substituted species $\mathrm{V}$.

$$
\begin{aligned}
\left(\eta^{5}-\mathrm{C}_{5} \mathrm{H}_{5}\right)_{2} \mathrm{NbCl}\left(\mathrm{PMe}_{3}\right)^{+} & \stackrel{\mathrm{S}}{\rightleftarrows}\left(\eta^{5}-\mathrm{C}_{5} \mathrm{H}_{5}\right)_{2} \mathrm{NbS}\left(\mathrm{PMe}_{3}\right)^{2+} \\
& \begin{array}{c}
\downarrow \mathrm{OPPh}_{3} \\
\left(\eta^{5}-\mathrm{C}_{5} \mathrm{H}_{5}\right)_{2} \mathrm{Nb}\left(\mathrm{OPPh}_{3}\right)\left(\mathrm{PMe}_{3}\right)^{2+}
\end{array}
\end{aligned}
$$


Alternatively, cationic halide complexes can be easily prepared from niobium(IV) derivatives by halide abstraction in the presence of the ligand.

$$
\begin{aligned}
&\left(\eta^{5}-\mathrm{C}_{5} \mathrm{H}_{5}\right)_{2} \mathrm{NbCl}_{2} \underset{-\mathrm{AgCl}}{\stackrel{\mathrm{AgBF}_{4}+\mathrm{L}}{\longrightarrow}}\left(\eta^{5}-\mathrm{C}_{5} \mathrm{H}_{5}\right)_{2} \mathrm{NbClL}^{+} \\
&\left(\mathrm{VI}, \mathrm{L}=\mathrm{CH}_{3} \mathrm{CN}\right. \\
&\text { VII, } \left.\mathrm{L}=\mathrm{OPPh}_{3}\right)
\end{aligned}
$$

When acrylonitrile was used the product was identified as $\left\{\left[\left(\eta^{5}-\mathrm{C}_{5} \mathrm{H}_{5}\right)_{2} \mathrm{NbCl}\right]_{2}(\mu-\right.$ $\left.\left.\mathrm{CH}_{2}=\mathrm{CH}-\mathrm{CN}\right)\right\}^{2+}$ (VIII) from the analytical composition shown in Table 1.

These cationic complexes are stable as solids under dry $\mathrm{N}_{2}$ and soluble in polar solvents. Their solutions are easily oxidized at air to give $\left\{\left[\left(\eta^{5}-\mathrm{C}_{5} \mathrm{H}_{5}\right)_{2} \mathrm{NbCl}\right]_{2}(\mu\right.$ O) $\}^{2+}[6]$.

The IR spectra of IV-VIII show a broad absorption at $1070 \mathrm{~cm}^{-1}$, which along with the weak band at 530 and $360 \mathrm{~cm}^{-1}$ are assigned to free $\mathrm{BF}_{4}^{-}$[7]. Characteristic $\left(\eta^{5}-\mathrm{C}_{5} \mathrm{H}_{5}\right)$ absorptions are observed at $820,260 \mathrm{~cm}^{-1}$.

The halide derivatives IV, VI-VIII show the $\nu(\mathrm{Nb}-\mathrm{Cl})$ stretching vibration at $250-260 \mathrm{~cm}^{-1}$. Complexes IV and $V$ show charasteristic $\mathrm{PMe}_{3}$ bands at 1290 and $950 \mathrm{~cm}^{-1}$, and $V$ shows additional bands at 1190,700 and $540 \mathrm{~cm}^{-1}$ for $\mathrm{OPPh}_{3}$, which are also observed for VII.

Complexes VI and VIII show the $\nu(\mathrm{C} \equiv \mathrm{N})$ stretching frequency at 2280 and 2260 $\mathrm{cm}^{-1}$, respectively, displaced by $40-60 \mathrm{~cm}^{-1}$ to higher frequencies (2220 for free ligands) as expected for the coordination of nitrile through the $\mathrm{N}$ [8]. The $\nu(\mathrm{C}=\mathrm{C})$ bands at 1610 and $1650 \mathrm{~cm}^{-1}$ in free acrylonitrile are not observed for complex VIII. Because of this and the analytical composition we suggest a structure with the ligand bridging both metal atoms through the $\mathrm{N}$ and the olefinic system. We cannot, however, confirm this type of coordination because an NMR study is prevented by the paramagnetism of the compound ( $\mu_{\mathrm{eff}} 2.78 \mathrm{BM}$ at room temperature for the dimer).

The rest of the cationic niobium(IV) complexes are paramagnetic with $\mu_{\text {eff }}$ values at room temperature between 1.38 and $1.52 \mathrm{BM}$, as shown in Table 1 .

Complex V shows a conductivity in acetone (see Table 1 ) corresponding to a $1 / 2$ electrolyte [9] in agreement with its formulation. In contrast the halide complexes show substantial conductivities, indicating extensive dissociation of the halide in polar solvents.

\section{Attemps to obtain alkylniobium(III) complexes}

Several attempts to alkylate complex I using $\mathrm{LiR}\left(\mathrm{R}=\mathrm{Me}, \mathrm{CH}_{2} \mathrm{CMe}_{3}, \mathrm{CH}_{2} \mathrm{Ph}\right)$ gave only decomposition products. In an attempt to isolate these alkyl derivatives we tried to reduce the haloalkylniobium(IV) complexes, obtained as described elsewhere for $\mathrm{R}=\mathrm{Me}[10]$ and $\mathrm{R}=\mathrm{CH}_{2} \mathrm{CMe}_{3}[11]$, in the presence of $\mathrm{PMe}_{3}$. Only untractable residues were obtained when $\mathrm{R}=\mathrm{Me}$. The reduction of the haloneopentyl complex gave a blue oil containing the alkyl derivative, as shown by ${ }^{1} \mathrm{H}$ NMR spectrum, which presented three singlets at $\delta 0.87 \mathrm{ppm}\left(\mathrm{PMe}_{3}\right), \delta 1.33 \mathrm{ppm}\left(\mathrm{CMe}_{3}\right)$ and $\delta 5.52$ ppm $\left(\eta^{5}-\mathrm{C}_{5} \mathrm{H}_{5}\right)$ with relative intensities $9 / 9 / 10$. The complex could not be obtained as a solid.

The halobenzylniobium(IV) complex could not be isolated because the dibenzyl was always preferently formed [3]. In an attempt to obtain the halobenzyl derivative 


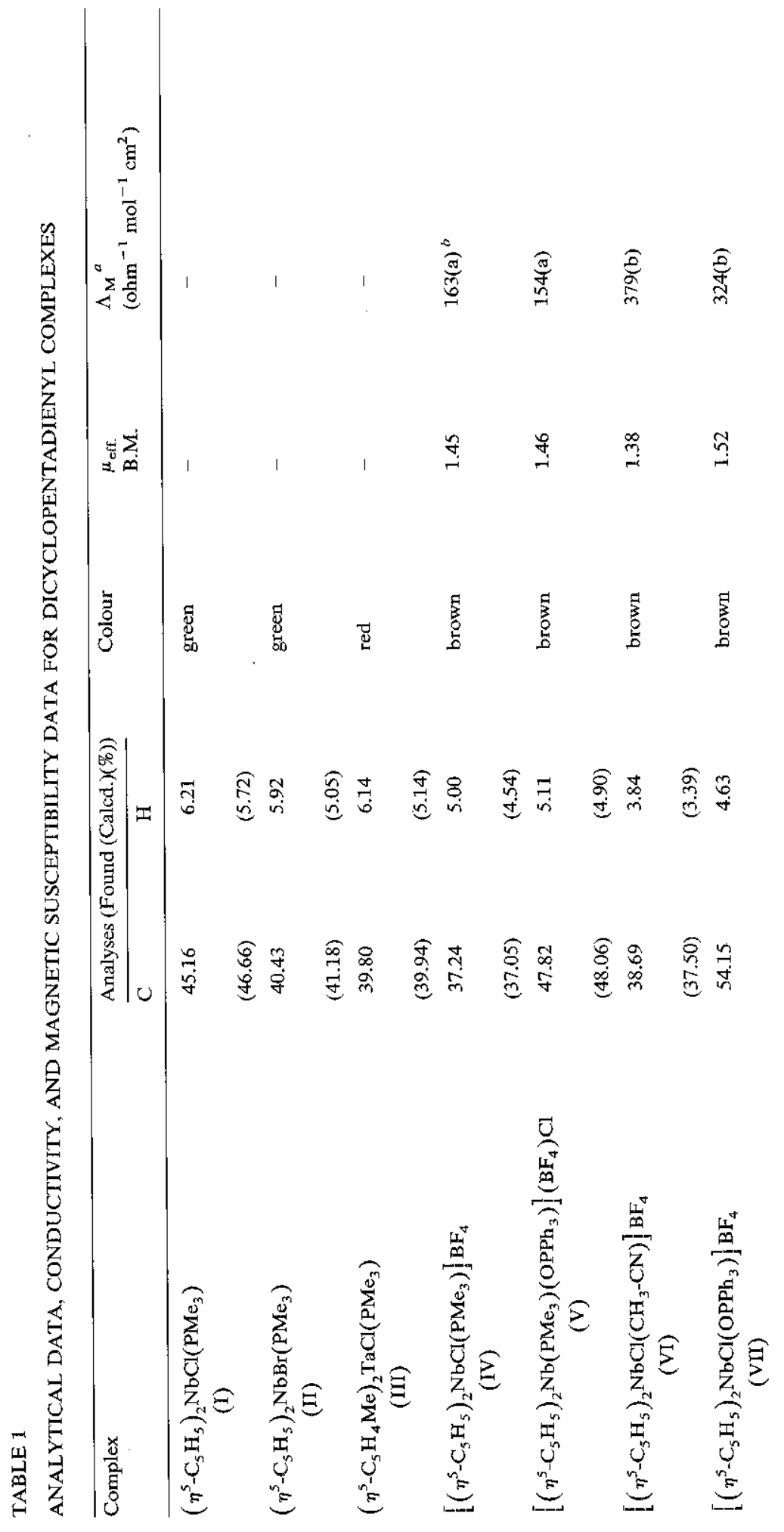




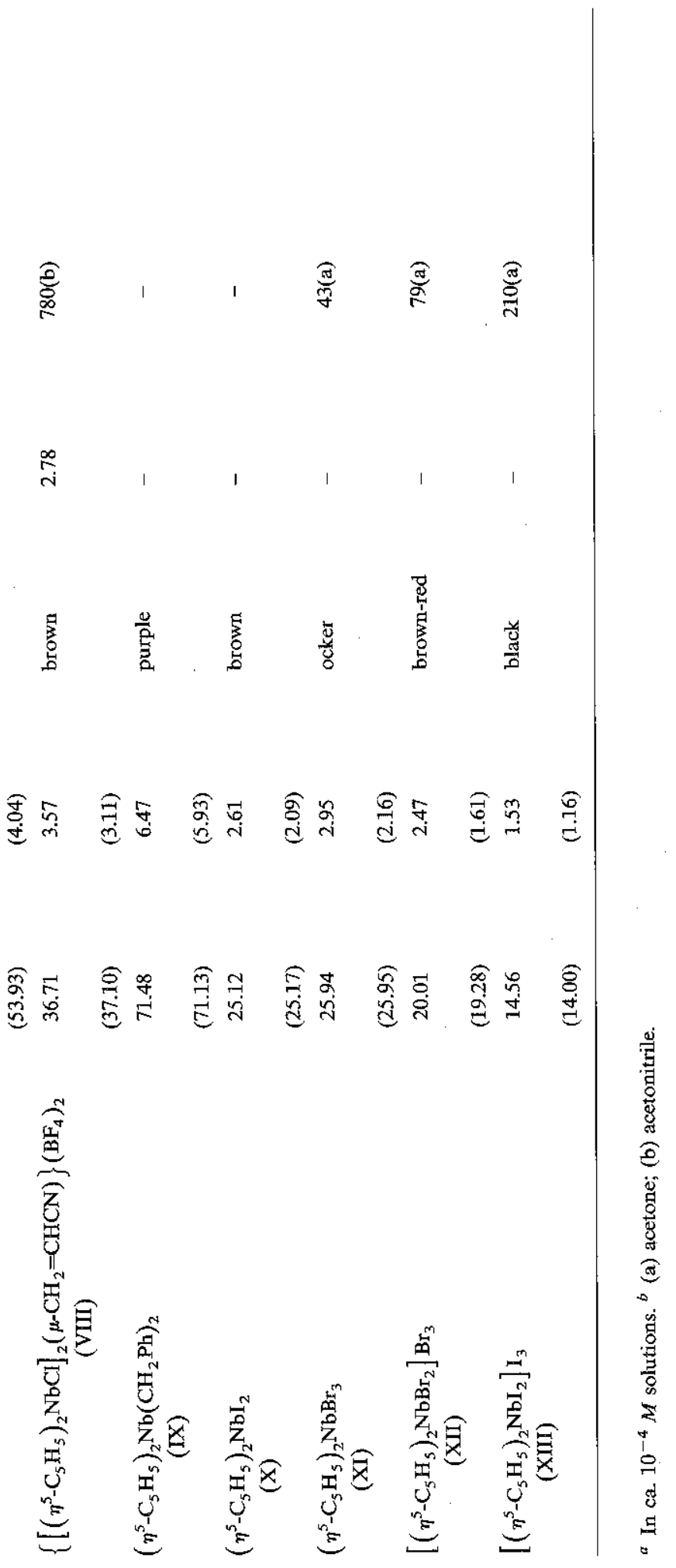


we carried out reactions of IX with halogens. Both $\mathrm{Nb}-\mathrm{C}$ bonds were broken to give only haloniobium(IV) complexes, which were oxidized to neutral niobium(V) or their corresponding cationic species by an excess of halogen, as shown by the following equation:

$$
\begin{array}{ccc}
\left(\eta^{5}-\mathrm{C}_{5} \mathrm{H}_{5}\right)_{2} \mathrm{NbBz}_{2} \rightarrow \underset{\mathrm{X}_{2}}{\rightarrow}\left(\eta^{5}-\mathrm{C}_{5} \mathrm{H}_{5}\right)_{2} \mathrm{NbX}_{2} \rightarrow & \left(\eta^{5}-\mathrm{C}_{5} \mathrm{H}_{5}\right)_{2} \mathrm{NbX}_{3} \\
(\mathrm{IX}) & (\mathrm{X}, \mathrm{X}=\mathrm{I}) & (\mathrm{IX}, \mathrm{X}=\mathrm{Br}) \\
& & \downarrow \\
& & \left(\eta^{5}-\mathrm{C}_{5} \mathrm{H}_{5}\right)_{2} \mathrm{NbX}_{2}^{+} \mathrm{X}_{3}^{-} \\
& (\mathrm{XII}, \mathrm{X}=\mathrm{Br} \\
& & \mathrm{XIII}, \mathrm{X}=\mathrm{I})
\end{array}
$$

Addition of $\mathrm{I}_{2}$ gives the diiodo complex $\mathrm{X}$, so that niobium(IV) is not oxidized without prior breaking of both $\mathrm{Nb}-\mathrm{C}$ bonds. An excess of $\mathrm{I}_{2}$ leads to oxidation to niobium(V), but the triiodo complex cannot be isolated pure because transformation into the cationic XIII takes place simultaneously, and the solids obtained have an intermediate composition. XIII can be isolated as a crystalline solid when the iodine in $\mathrm{a} \mathrm{Nb} / \mathrm{I}_{2}$ ratio of $1 / 3.5$ is added to $\mathrm{IX}$.

Addition of $\mathrm{Br}_{2}$ gives the tribromo complex XI directly, and it is not possible to isolate the intermediate dibromo compound. This behaviour shows that oxidation to niobium( $(\mathrm{V})$ precedes $\mathrm{Nb}-\mathrm{C}$ bond breaking. The addition of an excess of $\mathrm{Br}_{2}$ also gives the cationic species XII under these conditions.

All the halide complexes are stable under dry $\mathrm{N}_{2}$ as solids. $\mathrm{X}$ is very sensitive towards oxidation in solution, and XI-XIII are readily hydrolized as solids and in solution.

All the niobium(V) complexes are dissociated in acetone. The equivalent conductivity of XI is $43 \mathrm{ohm}^{-1} \mathrm{~mol}^{-1} \mathrm{~cm}^{2}$, suggesting the existence of the equilibrium:

$\left(\eta^{5}-\mathrm{C}_{5} \mathrm{H}_{5}\right)_{2} \mathrm{NbBr}_{3} \rightleftarrows\left(\eta^{5}-\mathrm{C}_{5} \mathrm{H}_{5}\right)_{2} \mathrm{NbBr}_{2}{ }^{+} \mathrm{Br}^{-}$

The conductivity of XI is lower than expected for a $1 / 1$ electrolyte, probably because of some association as represented in the following equation.

$\left(\eta^{5}-\mathrm{C}_{5} \mathrm{H}_{5}\right)_{2} \mathrm{NbBr}_{2}{ }^{+} \mathrm{Br}_{3}{ }^{-} \rightleftarrows\left(\eta^{5}-\mathrm{C}_{5} \mathrm{H}_{5}\right)_{2} \mathrm{NbBr}_{3}+\mathrm{Br}_{2}$

This association is not observed for the iodo complex XIII, which instead shows the conductivity expected for a $2: 1$ electrolyte indicating that dissociation is complete. $\left(\eta^{5}-\mathrm{C}_{5} \mathrm{H}_{5}\right)_{2} \mathrm{NbI}_{2}+\stackrel{+\mathrm{S}}{\rightleftarrows}\left(\eta^{5}-\mathrm{C}_{5} \mathrm{H}_{5}\right)_{2} \mathrm{NbIS}^{2+}+\mathrm{I}^{-}$

The IR spectra of all the complexes in the solid state show the characteristic absorptions of the $\mathrm{C}_{5} \mathrm{H}_{5}$ ring at $3060-3070,1120,1000$ and $840-860 \mathrm{~cm}^{-1}$. The ${ }^{1} \mathrm{H}$ NMR spectra of XI and XII in chloroform- $d_{1}$ show a singlet at $\delta 6.40-6.45 \mathrm{ppm}$, indicating that both rings are equivalent. Similarly XIII shows a singlet at $\delta 6.45$ ppm in dimethylsulphoxide- $d_{6}$. In acetone- $d_{6}$ multiplets are always observed because of the formation of several solvated species.

\section{Experimental}

All experiments were performed under dry $\mathrm{N}_{2}$ in Schlenk-type glassware. Solvents were previously distilled under $\mathrm{N}_{2}$, dried by standard methods, and degassed before 
use. The $\mathrm{C}$ and $\mathrm{H}$ analyses were performed with a Perkin-Elmer 240B microanalyser.

Conductivities were measured in a LF-42 conductimeter. Magnetic measurements were carried out by the Faraday method at room temperature with a Bruker magnet System. IR spectra were recorded as $\mathrm{KBr}$ pellets or Nujol mulls between CsI plates using a Perkin-Elmer 457 spectrophotometer. ${ }^{1} \mathrm{H}$ NMR spectra were run on a Varian FT-80A instrument in chloroform- $d_{1}$, acetone- $d_{6}$ or dimethylsulphoxide- $d_{6}$.

$\left(\eta^{5}-\mathrm{C}_{5} \mathrm{H}_{5}\right)_{2} \mathrm{NbX}_{2}(\mathrm{X}=\mathrm{Cl}, \mathrm{Br})$ were prepared as previously described $[12,13]$, as was $\left(\eta^{5}-\mathrm{C}_{5} \mathrm{H}_{4} \mathrm{Me}\right){ }_{2} \mathrm{TaCl}_{2}$ [14]. $\mathrm{PMe}_{3}$ was obtained as previously described [15] and was finally converted into the stoichiometric adduct $\left(\mathrm{AgI} \cdot \mathrm{PMe}_{3}\right)$. $\left(\eta^{5}-\right.$ $\left.\mathrm{C}_{5} \mathrm{H}_{5}\right)_{2} \mathrm{Nb}\left(\mathrm{CH}_{2} \mathrm{Ph}\right)_{2}$ was isolated from the dichloride by reaction with $\left(\mathrm{CH}_{2} \mathrm{Ph}\right)_{2} \mathrm{Mg} \cdot 2 \mathrm{THF}[16]$.

\section{$\left(\eta^{5}-C_{5} H_{4} R\right)_{2} M X\left(P M e_{3}\right) . I, I I$ and $I I I$}

THF $(30 \mathrm{ml})$ was added to a mixture of $\left(\eta^{5}-\mathrm{C}_{5} \mathrm{H}_{4} \mathrm{R}\right)_{2} \mathrm{MX}_{2}(2.5 \mathrm{mmol}), 10 \%$ $\mathrm{Na} / \mathrm{Hg}$ amalgam $\left(2.5 \mathrm{mmol}\right.$ ) and an excess of $\mathrm{PMe}_{3}$. After stirring for $2 \mathrm{~h}$ at room temperature the solid was filtered off, and I, II and III were obtained as crystalline solids by evaporation of the solvent and after washing with hexane and drying under reduced pressure. Yields 90,70 , and $50 \%$, respectively.

$\left[\left(\eta^{5}-C_{5} H_{5}\right)_{2} \mathrm{Nb}\left(\mathrm{PMe}_{3}\right) \mathrm{Cl}\right]\left(\mathrm{BF}_{4}\right)$ (IV) and $\left[\left(\eta^{5}-\mathrm{C}_{5} \mathrm{H}_{5}\right)_{2} \mathrm{Nb}\left(\mathrm{PMe}_{3}\right)\left(\mathrm{OPPh}_{3}\right)\right](\mathrm{Cl})\left(\mathrm{BF}_{4}\right)$ (V)

$0.116 \mathrm{~g}(0.6 \mathrm{mmol})$ of $\mathrm{AgBF}_{4}$ was added to a solution of I in $30 \mathrm{ml}$ of THF and the mixture was stirred overnight. After filtration the solid was extracted with acetone. Concentration of the solution and addition of toluene gave crystalline brown IV. The acetone solution was treated with-an excess of $\mathrm{OPPh}_{3}$, stirred for $4 \mathrm{~h}$, filtered, and evaporated to give V. Yields ca. 50\%.

$\left[\left(\eta^{5}-C_{5} H_{5}\right)_{2} \mathrm{NbClL}\right]\left(\mathrm{BF}_{4}\right) \quad(\mathrm{VI}, \quad \mathrm{VII})$ and $\left\{\left[\left(\eta^{5}-\mathrm{C}_{5} \mathrm{H}_{5}\right)_{2} \mathrm{NbCl}\right]_{2}\left(\mu-\mathrm{CH}_{2}=\mathrm{CHCN}\right)\right\}-$ $\left(\mathrm{BF}_{4}\right)_{2}(\mathrm{VIII})$

$0.130 \mathrm{~g}(0.7 \mathrm{mmol})$ of $\mathrm{AgBF}_{4}$ was added to a solution of $0.2 \mathrm{~g}(0.7 \mathrm{mmol})$ of $\left(\eta^{5}-\mathrm{C}_{5} \mathrm{H}_{5}\right)_{2} \mathrm{NbCl}_{2}$ in $30 \mathrm{ml}$ of acetonitrile or acrylonitrile. The precipitate was filtered off and the solution was evaporated under reduced pressure to give an oil, which was treated with pentane to give crystalline VI or VIII.

A similar reaction in acetone gave a solution which was filtered on to $0.195 \mathrm{~g}(0.7$ mmol) of $\mathrm{OPPh}_{3}$. The solution obtained was worked up as described above to give VII, which was washed with pentane and dried under vacuum. Yields $75 \%$.

$\left(\eta^{5}-\mathrm{C}_{5} \mathrm{H}_{5}\right)_{2} \mathrm{Nb}\left(\mathrm{CH}_{2} \mathrm{Ph}\right)_{2}$

A mixture of $2.00 \mathrm{~g}(6.8 \mathrm{mmol})$ of $\left(\eta^{5}-\mathrm{C}_{5} \mathrm{H}_{5}\right)_{2} \mathrm{NbCl}_{2}$ and $2.38 \mathrm{~g}(6.8 \mathrm{mmol})$ of $\left(\mathrm{CH}_{2} \mathrm{Ph}\right)_{2} \mathrm{Mg} \cdot 2 \mathrm{THF}$ in $100 \mathrm{ml}$ of THF was stirred for $3 \mathrm{~h}$ at room temperature. After filtration the solution was evaporated to dryness and the residue was extracted with warm benzene. Evaporation of the solvent under reduced pressure to a volume of $25 \mathrm{ml}$ give IX as purple crystals. Yields $80 \%$.

Reaction of $I X$ with $I_{2}$

$0.40 \mathrm{~g}(1.58 \mathrm{mmol})$ of $\mathrm{I}_{2}$ was added to $0.32 \mathrm{~g}(0.79 \mathrm{mmol})$ of IX in diethyl ether $(50 \mathrm{ml})$ and the mixture was stirred for $1 \mathrm{~h}$ at room temperature. The solid obtained 
was filtered, washed with diethyl ether, dried under vacuum, and characterized as $\mathrm{X}$. Yield $90 \%$. The same reaction with $0.70 \mathrm{~g}(2.78 \mathrm{mmol})$ of $\mathrm{I}_{2}$ gave black crystalline XIII after washing with diethyl ether and drying under vacuum. Yield $90 \%$. Use of intermediate amounts of $\mathrm{I}_{2}$ gave only impure products.

Reaction of IX with $\mathrm{Br}_{2}$

$4.8 \mathrm{mmol}$ of $\mathrm{Br}_{2}(0.24 \mathrm{ml})$ were added to a solution of $0.76 \mathrm{~g}(1.92 \mathrm{mmol})$ of IX in $50 \mathrm{ml}$ of diethyl ether and the mixture was stirred for $1 \mathrm{~h}$. The crystalline solid was filtered off, washed twice with diethyl ether, and dried under vacuum to give XI. Yield $90 \%$.

The same product in lower yield was always obtained when a smaller amount of $\mathrm{Br}_{2}$ was used. When the reaction is carried out with an excess of $\mathrm{Br}_{2}(6.8 \mathrm{mmol}), \mathrm{XII}$ was obtained as a crystalline brown orange solid after being washed with diethyl ether and dried under vacuum. Yield $90 \%$.

\section{Acknowledgements}

The authors gratefully acknowledge financial support from the Comsion Asesora de Investigación Científica y Técnica (Spain).

\section{References}

1 C. Sanchez, D. Vivien, J. Livage, J. Sala Pala, B. Viard and J.E. Guerchais, J. Chem. Soc. Dalton Trans., (1981) 64.

2 R. Serrano and P. Royo, J. Organomet. Chem., 247 (1983) 33.

3 R.S. Threlkel, J.E. Bercaw, J. Am. Chem. Soc., 103 (1981) 2650.

4 R.Markham, E.A. Dietz and D.R. Martin, J. Inorg. Nuc. Chem., 35 (1973) 2659.

5 D.A. Lemenovskii, T.V. Baukova and V.P. Fedin, J. Organomet. Chem., 132 (1977) C14.

6 W.E. Douglas and M.L.H. Green, J. Chem. Soc. Dalton Trans,, (1972) 1796.

7 A.S. Quist, J.B. Bates and G.E. Boyd, J. Chem. Phys., 54 (1971) 4896.

8 R.A. Walton, Can. J. Chem., 44 (1966) 1480.

9 W.J. Geardy, Coord. Chem. Rev., 7 (1971) 81.

10 E.E.H. Otto and H.H. Brintzinger, J. Organomet. Chem., 170 (1979) 209.

11 P.B. Hitchcock, M.F. Lappert and C.R.C. Milrre, J. Chem. Soc. Dalton Trans., (1981) 180.

12 C.R. Lucas and M.L.H. Green, J. Chem. Soc., Chem. Comm., (1972) 1005.

13 L. Acedo, A. Otero and P. Royo, J. Organomet. Chem., 258 (1983) 181.

14 M.J. Bunker, A. De Cian, M.L.H. Gren, J.E. Moreau and N. Siganporia, J. Chem. Soc., (1980) 2155.

15 J.G. Evans, P.L. Guggin, R.J. Goodfellow and J.G. Smith, J. Chem. Soc. A, (1968) 464.

16 R.R. Schrock, J. Organomet. Chem., 122 (1976) 222. 